Proc. Estonian Acad. Sci. Eng., 2006, 12, 4, 419-426

\title{
Wear of hard coatings, evaluated by means of kaloMax
}

\author{
Vitali Podgursky, Andre Gregor, Eron Adoberg and Priit Kulu \\ Department of Materials Engineering, Tallinn University of Technology, Ehitajate tee 5, 19086 \\ Tallinn, Estonia; vitali.podgurski@ttu.ee \\ Received 2 June 2006, in revised form 25 September 2006

\begin{abstract}
A spherical cap grinder (kaloMax) was employed to evaluate the wear resistance of hard coatings. Simplicity is the attractive advantage of the test. A comparative study of TiN and AlTiN coatings was carried out to elucidate capabilities and limitations of the technique. The relatively high uncertainty of measurement suggests that the test can be used only for qualitative evaluation of wear.
\end{abstract}

Key words: hard coatings, wear, ball-cratering.

\section{INTRODUCTION}

Hard coatings have been widely used to increase the wear resistance of cutting and forming tools. Various methods of coating deposition have found industrial application. One successful approach is physical vapor deposition (PVD) technique. The arc ion plating combines an arc evaporation process with ion bombardment during the coating deposition, which helps to achieve better stoichiometric balance within the coating. Presently, development of (Ti,Al)N based multilayer and nanocomposite coatings are the most important trends in the hard coating industry $\left[{ }^{1,2}\right]$.

In order to characterize the quality of a coating, evaluation of a number of properties is essential. Hardness, friction coefficient, roughness, thickness, wear and oxidation resistance have primary importance. These properties cannot be evaluated for each sample, due to their size, shape and weight. A reference sample is mounted into the chamber to control the overall quality of the coating, grown in batch deposition $\left[{ }^{3}\right]$. Immediately after deposition the thickness, hardness, adhesion and surface smoothness of the coating, grown on the reference sample, can be assessed. Among them, the hardness and thickness can be 
quantitatively evaluated by means of indentation and ball-cratering (kaloMax) tests, respectively. The adhesion and surface quality can be qualitatively characterized by means of microscopic examination of the coating fracture, occurring under heavy load (Rockwell adhesion test) and by morphology of the coating, respectively. The present work intends to investigate a practical implementation of the ball-cratering (micro-abrasion) test to estimate the wear from the volume of the grinded crater. Therefore an evaluation of the uncertainty of the measurement is of critical importance.

The kaloMax of BAQ is a spherical cap grinder, originally developed for the determination of the coating thickness. The result of the grinding process depends on both parts of the tribosystem, of the sample and kaloMax. The kaloMax parameters, which influence the result, are the following: grinding paste, number of revolutions, grinding period, diameter and normal force exerted by the ball $\left[{ }^{4}\right]$. On the other hand, the analysis of the sample parameters becomes more elaborate because of several wear phenomena. Generally, abrasive, tribochemical (tribo-oxidation), adhesive and surface fatigue processes are considered as the main mechanisms of the hard coating wear $\left[{ }^{5,6}\right]$.

Ball-cratering techniques are used by many authors $\left[{ }^{7,8}\right]$. An advantage of kaloMax is the construction of the driveshaft, preventing horizontal and vertical movement of the ball, which greatly reduces the uncertainty of measurement. Recently, a more advanced kaloMax NT was developed, enabling the wear coefficient to be deduced from a volume of the wear crater, load (normal force on the sample) and sliding distance $\left[{ }^{9}\right]$. The kaloMax used in the present work is not equipped with a gauge to measure the normal force on the sample.

Due to the mentioned variety of wear phenomena, the wear tests can be classified into a number of categories, including machinery field, system and component bench and model and laboratory tests $\left[{ }^{6}\right]$. The ball-cratering test can be considered as a model laboratory test. It should be stressed that this test differs from traditional techniques such as pin-on-disk $\left[^{7}\right]$. Therefore, the correlation with other types of tests demands a conservative estimation.

\section{EXPERIMENTAL}

\subsection{Materials}

The deposition of TiN and AlTiN coatings was carried out in the arc plating PVD unit PLATIT, using LAteral Rotating ARC-Cathodes (LARC) technology. AlTiN were deposited from TiAl alloy cathode with Ti to $\mathrm{Al}$ ratio of 30/70. The deposition temperature was $450^{\circ} \mathrm{C}$ and the thickness of the coatings was $2.5 \mu \mathrm{m}$. The basic properties of TiN and AlTiN coatings can be found in $\left[^{3}\right]$.

The AISI 304 (Avesta Sheffield Inc.) steel was used as the substrate. Prior to deposition, all specimens were polished on the emery paper and with $1 \mu \mathrm{m}$ diamond suspension, followed by cleaning in the ultrasonic bath with the detergent. Immediately after the cleaning procedure, the samples were placed 
into the vacuum chamber and mounted on the sample holder. Finally, the samples were sputter-cleaned in the argon plasma.

\subsection{Wear tests}

Unlubricated sliding wear tests were carried out. The diameter of the ball was $30 \mathrm{~mm}$. The ball speed and grinding period were varied between 100-1000 rpm and $20-120 \mathrm{~s}$, respectively. The meticulous measurements of the spherical gap diameter in perpendicular directions were carried out, followed by averaging. The statistical sample size was equal to 10 for each type of the experiment, i.e. for the fixed ball speed and grinding period.

\subsection{Uncertainty evaluation}

An example of the spherical gap observed on the surface of TiN coating (300 rpm, $120 \mathrm{~s}$ ) is shown in Fig. 1.

Grinding periods and ball speeds are fixed parameters. Therefore kaloMax is checked to be certain that dimensions of the gap are in close agreement with the technical specification of it, namely the diameter of the gap may not be less than $0.1 \mathrm{~mm}\left[{ }^{4}\right]$. The spherical gap volume $V$ can be calculated as

$$
V=\frac{3 \pi h^{2} R-\pi h^{3}}{3},
$$

where $R$ is the radius of the ball and $h$ is the height of the gap. The gap diameter is equal to 2a (Fig. 2). The spherical gap with diameter of $0.1 \mathrm{~mm}$ is $0.1 \mu \mathrm{m}$ in depth and possesses the volume equal to $2.0 \times 10^{-7} \mathrm{~mm}^{3}$.

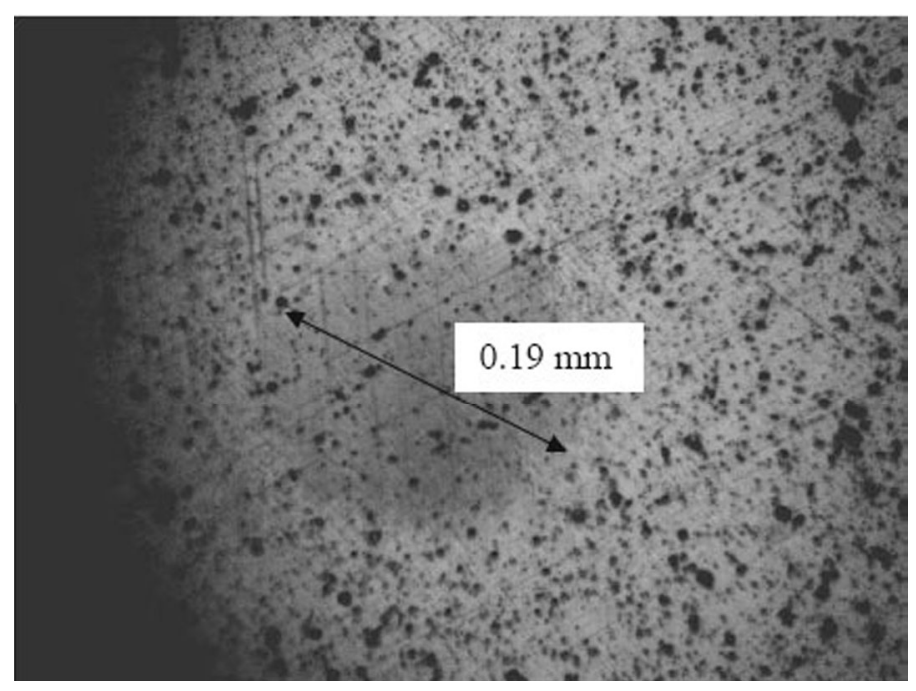

Fig. 1. The spherical gap observed on top of the TiN coating (300 rpm, $120 \mathrm{~s}$ ). 


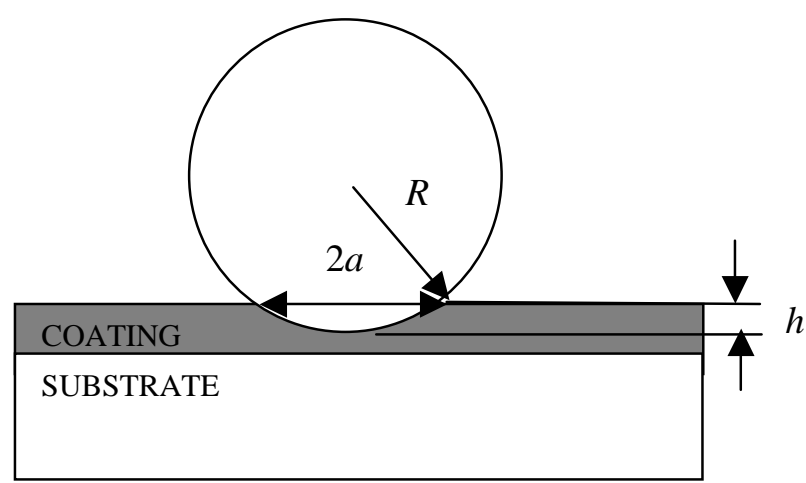

Fig. 2. Set-up of the ball-cratering test.

Uncertainty of the spherical gap volume can be estimated by a method described in $\left[{ }^{10,11}\right]$, including a combination of types $\mathrm{A}$ and $\mathrm{B}$ of the standard uncertainty evaluation $\left[{ }^{11}\right]$. The spherical gap is grinded by the ball, followed by the determination of the gap diameter with the optical microscope. Eventually the standard uncertainty of the in-plane distance $u(x)$ (or $u(y)$ ) depends on four input quantities: the ball diameter, friction coefficient, normal force and standard uncertainty of the microscope.

In the case of the type A, the standard uncertainty of the input quantities is evaluated by the statistical analysis of the series of observation. An averaged value of the standard uncertainty of the in-plane distance was found equal to $0.008 \mathrm{~mm}$. The expanded uncertainty of the experiment $U(x)$ is equal to $k \times u(x)$, where $k$ depends on the probability distribution of the quantity $x$ and the level of confidence. In most of calibrations the output distribution can be reasonably supposed to have the normal distribution and for the level of confidence equal to $95 \%$ we have $k=2.0$; therefore a tolerance of the in-plane distance is $\Delta(x)= \pm 0.016 \mathrm{~mm}$.

Errors, originated from the particular sources can be assessed by the type B of evaluation. The shape tolerance of the ball is determined by the standard DIN 5401. The ball up to $38.1 \mathrm{~mm}$ in diameter has the tolerance equal to $\pm 0.0115 \mathrm{~mm}$. The standard uncertainty $u_{\text {ball }}(x)$ can be calculated as

$$
u_{\text {ball }}(x)=\frac{\Delta x}{2 \sqrt{3}}=0.003 \mathrm{~mm},
$$

assuming random distribution (in the limit of the worst case). The standard uncertainty of the microscope resolution $u_{\text {micr }}(x)$ can be estimated from the least division of the scale of the microscope, which is equal to $0.01 \mathrm{~mm}$. Therefore, based on the worst case, this uncertainty is

$$
u_{\text {micr }}(x)=\frac{\Delta x}{2 \sqrt{3}}=0.003 \mathrm{~mm} .
$$


The combined standard uncertainty of the in-plane distance is estimated as

$$
u(x)=\sqrt{u_{\text {ball }}^{2}(x)+u_{\text {micr }}^{2}(x)+u_{\mathrm{ff}}^{2}(x)},
$$

where $u_{\mathrm{ff}}(x)$ is the uncertainty of all other sources. By virtue of independence of $u(x)$ from the type of the standard uncertainty evaluation, it follows that $u_{\mathrm{ff}}(x)=0.006 \mathrm{~mm}$.

The error in $R$ is less than $1 \%$, therefore the accuracy of measurement in the $z$ direction depends on the accuracy of the gap diameter measurement $\left[{ }^{4}\right]$. Since

$$
h=R-\sqrt{R^{2}-a^{2}},
$$

the uncertainty in $z$ direction might be estimated as $\Delta(x) / 2 a$, i.e. in the case of the gap with diameter of $0.15 \mathrm{~mm}$, the uncertainty of the depth is equal to $0.016 / 0.15 \times 100 \%=11 \%$, and for $0.2 \mathrm{~mm}$ it is $8 \%$.

Based on the well-known expressions of the uncertainties

$$
\begin{gathered}
\Delta(A \pm B)=\Delta A+\Delta B, \\
E_{A \times B}=E_{A}+E_{B},
\end{gathered}
$$

where $E_{A}=\Delta A /|A|$, the wear volume tolerance $\Delta(V)$ is in the case of the spherical gap with a diameter of $0.15 \mathrm{~mm}$ equal to about $22 \%$ and for diameter $0.2 \mathrm{~mm}$ equal to $16 \%$.

\section{RESULTS AND DISCUSSION}

The uncertainty estimation shows that the ball-cratering test possesses an acceptable tolerance to be applied to qualitative comparative studies of wear. The main reasons of the relatively high uncertainty could be the normal force variation on the sample and to a lesser degree the wear of the ball. A replacement of the sample in the sample holder and a movement of the sample holder to a new position give rise to the normal force variation. The modified kaloMax NT is equipped with a gauge, enabling a control of the normal force on the sample. However, in principle, kaloMax could be used to the qualitative evaluation of the wear resistance of the reference samples in batch deposition.

Figure 3 shows the volume of the spherical gaps observed on top of TiN and AlTiN coatings. In spite of relatively high uncertainty of the wear volume, some features are recognizable. In the case of $\mathrm{TiN}$, it is apparent that between 200$400 \mathrm{rpm}$ the wear volume is smaller than for $100 \mathrm{rpm}$. This observation is in good agreement with the well-known decrease of the wear as the sliding speed approaches a limit (about $0.05-0.1 \mathrm{~m} / \mathrm{s}$ ) $\left.{ }^{1,7}\right]$; indeed, $100 \mathrm{rpm}$ corresponds to about $0.1 \mathrm{~m} / \mathrm{s}$. However, the effect is progressively reduced with the increase of the grinding period. In addition, the wear volume increases fast for TiN, if the speed exceeds $500 \mathrm{rpm}$. Evidently, under the test conditions, the wear depends on 

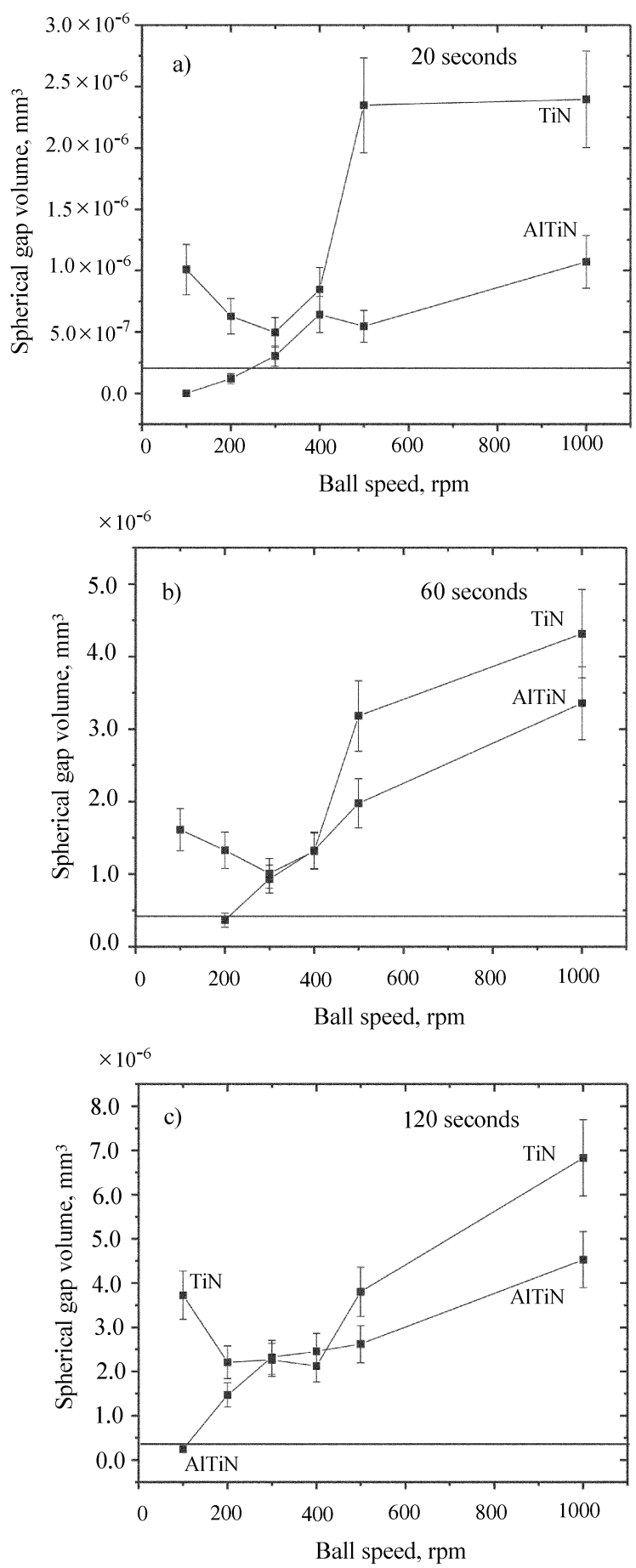

Fig. 3. The wear volume of the spherical gaps observed on top of TiN and AlTiN coatings for different grinding periods: a) $20 \mathrm{~s}$, b) $60 \mathrm{~s}$ and c) $120 \mathrm{~s}$. The bold line corresponds to the volume of the spherical gap with $0.1 \mathrm{~mm}$ in diameter. 
the covered distance and ball speed. In the case of AlTiN, the wear volume steadily increases independently of the grinding period. Probably, the aforementioned threshold is lower than $0.1 \mathrm{~m} / \mathrm{s}$.

The results can be explained by the mechanisms of wear. The abrasive wear is caused by hard or sharp-edged surface irregularities (two-body wear) and hard particles that get in between the friction pairs (three-body wear). From a conventional standpoint it follows that under the abrasive wear AlTiN should be more stable than TiN, because the hardness of AlTiN $\left(\mathrm{H}_{\mathrm{v}} 38 \mathrm{GPa}\right)$ is higher than that of $\mathrm{TiN}\left(\mathrm{H}_{\mathrm{V}} 24 \mathrm{GPa}\right)\left[^{3}\right]$. On the other hand, the wear performance of AlTiN coating is impaired, as a consequence of the relatively high friction coefficient of $(\mathrm{Ti}, \mathrm{Al}) \mathrm{N}$ based coatings deposited by the cathodic arc technique. For instance, AlTiN friction (fretting) coefficient is equal to 0.7 , in contrast to 0.55 for TiN coating $\left[{ }^{3}\right]$.

We observed iron oxide traces on the surface of coatings. Iron chips are formed due to the wear of the ball. The iron oxide debris were also found on top of the crater under similar unlubricated testing $\left[{ }^{8}\right]$. Indeed, scratches appear on the ball, which indicates to metal cutting on the surface of the ball. Therefore, a significant heating could be expected at the point of contact $\left[{ }^{5}\right]$, promoting tribochemical wear. High temperature and chemical reactions at the contact make sliding surfaces softer, thus decreasing their wear resistance $\left[{ }^{5}\right]$. It should be emphasized that softening of TiN and AlTiN coatings begins at about 500 and $900^{\circ} \mathrm{C}\left[{ }^{3}\right]$, respectively. This supposition could explain the fast increase of the wear volume, observed for TiN at about $500 \mathrm{rpm}$. In addition, authors of $\left[{ }^{8}\right]$ state that the debris change in colour depending on the composition of the coating. Naturally, formed on top of (Ti, $\mathrm{Al}) \mathrm{N}$ based coatings, $\mathrm{Al}_{2} \mathrm{O}_{3}$ layer increases the oxidation resistance. We believe that in the case of $\mathrm{AlTiN}$ hard $\mathrm{Al}_{2} \mathrm{O}_{3}$ particles, produced in the collision between the friction pair, could significantly increase the wear.

The adhesive wear occurs due to increasing affinity between surfaces. This mechanism could play an important role, particularly, in the case of dry sliding. However, no data is available to estimate the adhesion wear between the iron ball and tested coatings.

As a result of loading and unloading of the surface, the surface fatigue wear was observed, especially in rolling contact $\left[^{5}\right]$. The formation and propagation of cracks take place near the contact. Generally, compressive residual stresses play an inhibitory role, preventing the crack propagation through the coating $\left[^{1}\right]$. On the other hand, higher hardness of the coating leads to a higher value of the residual stress $\left[^{1}\right]$; therefore AlTiN should be more stable than the TiN coating.

\section{CONCLUSIONS}

The study of the wear of TiN and AlTiN coatings was carried out by using kaloMax. The results are in good agreement with the experimental data available in the literature. However, because of relatively high wear volume uncertainty, 
mainly due to variation in normal force on the sample, the results should be carefully analysed and compared with other types of tests, like pin-on-disc and reciprocating sliding wear tests. Thus the investigation has shown that the unlubricated ball-cratering test can provide a useful qualitative method for studying the wear resistance of hard coatings.

\section{ACKNOWLEDGEMENTS}

This work was supported by the Estonian Agency of Technology (grant No. EU20044). Authors wish to thank Prof. R. Laaneots from the Tallinn University of Technology for fruitful discussions concerning uncertainty evaluation.

\section{REFERENCES}

1. PalDey, S. and Deevi, S. C. Single layer and multilayer wear resistant coatings of (Ti,Al)N: a review. Mater. Sci. Eng. A, 2003, 342, 58-79.

2. Nanostructured coatings for high performance tools (PLATIT). Werkzeug Technik, 2003, 77, March.

3. http://www.platit.com

4. The BAQ kaloMax Manual, Version 1.01.

5. Holmberg, K. and Matthews, A. Coatings Tribology: Properties, Techniques and Aplications in Surface Engineering. Elsevier Science B.V., 1994.

6. Dyson, B. F., Loveday, M. S. and Gee, M. G. Materials Methodology and Standards for Structural Performance. Chapman and Hall, London, 1995.

7. Gee, M. G., Gant, A., Hutchings, I. M., Bethke, I., Schiffman, R. K., Van Acker, K., Poulat, S., Gachon, Y. and von Stebut, J. Progress towards standardization of ball cratering. Wear, 2003, 255, 1-13.

8. Gee, M. G. and Wicks, M. J. Ball crater testing for the measurement of the unlubricated sliding wear of wear-resistant coatings. Surf. Coat. Technol., 2000, 133-134, 376-382.

9. http://www.baq.de

10. Guide to the Expression of Uncertainty in Measurement. International Organization for Standardization, Geneva, 1995.

11. Laaneots, R. and Mathiesen, O. An Introduction to Metrology. TUT Press, Tallinn, 2006.

\section{Kõvapinnete kulumise hindamine kaloMax-seadme abil}

\section{Vitali Podgursky, Andre Gregor, Eron Adoberg ja Priit Kulu}

Nitritsete kõvapinnete kulumiskindluse hindamiseks on kasutatud kuivhõõrde ball-cratering-testi ja kaloMax-seadet, mis tagab kulumiskindluse kvalitatiivse hinnangu. Tulenevalt kulumise suhteliselt suurest hälbest tuleb tulemusi hoolikalt analüüsida ja kulumiskindluse hindamiseks kasutada ka teisi standardmeetodeid nagu pin-on-disc. 